\title{
Deveta dežela, podobi pojugoslovanske sedanjosti in antiutopična podoba (evropske?) prihodnosti
}

\author{
Mladen Pavičić \\ Eötvös Loránd Tudományegyetem, Budapest, Bölcsészettudományi Kar, Szláv Filológiai \\ Tánszék, Múzeum krt.4/D, HU-1088 Budapest,mladen.pavicic@gmail.com
}

\section{SCN II/2 [2009], 182-192}

\begin{abstract}
Osrednja tema prispevka je pojugoslovanska večjezičnost ljubljanskega blokovskega naselja Nove Fužine, kakor se kaže v romanih Fužinski bluz Andreja Skubica in Čefurji raus! Gorana Vojnovića. V uvodu je podanih nekaj zanimivih utrinkov o Evropi, slovenščini in slovanski samoupravni ljudovladi iz utopije Deveta dežela Josipa Stritarja, za konec pa nekaj misli o sodobni antiutopiji Spremeni me Andreja Blatnika, v kateri mračna vizija prihodnosti ne zadeva slovenskega jezika.
\end{abstract}

The central theme of this article is the post-Yugoslavic multilinguism of the block settlement Nove Fužine in Ljubljana, as it is presented in the novels Fužinski bluz by Andrej Skubic and Čefurji raus! by Goran Vojnović. The introduction includes some interesting thoughts about Europe, Slovene language and Slavic democratic self-government from the utopian The Ninth Land by Josip Stritar, while the conclusion presents a few thoughts on the modern antiutopian Change Me by Andrej Blatnik, where the dark vision of the future does not concern the Slovene language.

Ključne besede: Nove Fužine, jezik priseljencev, slovenščina, sociolekt, utopija, antiutopija

Key words: Nove Fužine, language of immigrants, Slovene language, sociolect, utopia, antiutopia

\section{Deveta dežela}

Zadnja leta me dogodki doma in po svetu vedno znova spomnijo na Stritarjevo Deveto deželo. Gre za njegov nedokončani utopični spis o idealni državi, katerega nekaj nadaljevanj je objavil leta 1878 v Zvonu pod psevdonimom Negoda. 
V Deveti deželi so ljudje neskončno pošteni, prijazni in gostoljubni. Na pogled so lepi in preprosto, a lepo oblečeni, lepe so tudi njihove zračne hiše. Prijazni so s služinčadjo in z živalmi, zato divjačina pred njimi ne beži, konji pa jih ubogajo kar brez vajeti. Za bolne, stare in onemogle je lepo poskrbljeno, v vsaki vasi imajo brezplačno knjižnico, kriminalna dejanja pa pomnijo le najstarejši. Seveda lepo skrbijo tudi za otroke, za vsak primer pa jih svarijo pred tem, kako kruto je lahko življenje, in sicer jih strašijo z Evropo:

Po daljšem izpraševanju sem zvedel, da je devetodeželanom Evropa nekaj takega, kakor je nam deveta dežela. V basnih, pripovedkah in pregovorih jo jemljó v misel; vendar ne tako kakor mi deveto deželo; za strašilo jo imajo otrokom! (Stritar 1954: 316)

Predvsem pa se v Deveti deželi govori najlepša, blagoglasna slovenščina, tudi zaradi tega, ker je Deveta dežela otok:

Rekel sem, da mi je mož odgovoril v najlepši slovenščini; to je še premalo. Lepa je bila ta slovenščina, kakor se pač nikjer ne govori po slovenskih deželah; še več, reči smem, da nisem še nikoli slišal tako lepega, tako blagoglasnega jezika. (Stritar 1954: 309)

Premišljevanje o tem, ali je Stritar s tem nedokončanim spisom mislil dobesedno, kot sta menila Fran Celestin in urednik njegovega Zbranega dela France Koblar (Stritar 1954: 447-448), ali pa gre za parodijo Bleiweisovih zamisli, kot mi je v telefonskem pogovoru 27. oktobra 2008 dejal zgodovinar Peter Vodopivec, ki se ne spomni, ali je to kje prebral ali gre za njegovo ugotovitev, presega okvire tega prispevka, z gotovostjo pa lahko zapišem, da Stritar ni slutil, kako bomo mi, Slovenci z začetka 21. stoletja, brali njegove ideje o ljudski demokraciji in samoupravljanju:

»Kako pa živite, pod cesarjem, ali kraljem ali kako?« /.../ »Ne, kaj takega ni pri nas; mi se sami vladamo." Ljudovlado torej imajo devetodeželjani; to je zopet slovansko! (Stritar 1954: 319)

Sodobna Slovenija vsekakor ni otok, marveč se nahaja v tej strašni Evropi, za seboj pa ima tudi skušnjo s samoupravno ljudovlado v slovanski državi. Kakšne sledi je ta doba pustila v slovenskem jeziku, presega okvire tega zapisa, nedvomno pa je ustvarila določene sociolekte. Blokovsko naselje Nove Fužine je eden tistih kotičkov naše domovine, v katerih je te sociolekte najpogosteje slišati.

\section{Nove Fužine}

V drugi polovici sedemdesetih let in v osemdesetih letih 20. stoletja - torej v času najbolj intenzivnega priseljevanja v Slovenijo - zgrajeno blokovsko naselje, v katerem po ocenah živi vsaj 18 tisoč ljudi, je z uradno 385 prebivalci na hektar (v resnici je številka verjetno še višja) najgosteje poseljeno območje v Sloveniji (Wikipedija: Nove Fužine).

Po podatkih, pridobljenih ob popisu prebivalstva leta 2002 , se je 57,4\% prebivalcev Novih Fužin opredelilo za Slovence; v Ljubljani je po teh podatkih 
manj Slovencev (33,6 \%) le v Rakovi Jelši, naselju s precej nelegalnimi stavbami brez kanalizacije in vodovoda, ki stoji na potresno in poplavno nevarnem močvirnem robu Ljubljane (Komac idr. 2007: 51). Vzrok za večjo gostoto neslovenskega prebivalstva v blokovskem naselju Nove Fužine tiči v tem, da je bilo v njem precejšnje število t. i. solidarnostnih stanovanj, »ki so bila namenjena prebivalcem z nižjimi dohodki« (Komac idr. 2007: 51). »Ker so priseljenci iz drugih jugoslovanskih republik pogosto sodili v kategorijo socialno šibkejšega sloja zaposlenih, « so prejeli precejšen delež teh stanovanj, poleg njih pa so bila v Novih Fužinah kadrovska stanovanja, ki so se dodeljevala tudi prebivalcem z višjimi dohodki (Komac idr. 2007: 51) - v tem je vzrok za nenavadno pestrost prebivalcev Novih Fužin. Spomnimo se, da tam stanujejo tudi donedavna ljubljanska županja Danica Simšič, zvezda televizijskega dnevnika Pop TV Matjaž Tanko in profesorica z ljubljanske slovenistike Erika Kržišnik. Soseska je na precej slabem glasu, statistike pa so s tem v popolnem nasprotju: Nove Fužine so po njih med varnejšimi ljubljanskimi soseskami (Močnik 2005: 26). Raziskava Mirovnega inštituta za Mestno občino Ljubljana je pokazala, da je bilo leta 2001 glede na število prebivalcev v Novih Fužinah manj kriminalnih dejanj kot v drugih mestnih skupnostih, prav tako to naselje po podatkih Rdečega križa ne izstopa po revščini - mesečno tu razdelijo okoli 200 paketov s hrano, v trikrat manjšem in neprimerno uglednejšem Trnovem pa 100. Naselje je infrastrukturno zelo dobro urejeno - ima zdravstveni dom, nekaj šol, banko, pošto, knjižnico, trgovine, številne lokale in obrtnike, urejene skupne površine, sprehajalne poti ob Ljubljanici in Fužinski grad z ljubljanskim arhitekturnim muzejem (Leskošek 2005: 32). Nekaj podobnega pove tudi Andrej Skubic:

/R/ealno gledano so Fužine super: krasno naselje, zelo solidno zgrajeni bloki, lep raz-
pored naselja, infrastruktura, vzdušje pa veliko bolj prijetno kot v vsaki Zupančičevi
jami. Lokali so domačni, ljudje se tam dobivajo in pozdravljajo. In čeprav je naselje
ogromno, ima svojo domačnost in idetiteto, ki je drugačna od ljubljanske. Mit o Fuži-
nah je seveda nekaj drugega. Že takoj ko se pripelješ v Fužine, vidiš grafit 'Vstopate
na lastno odgovornost!' Tukaj pa bo zanimivo, sem si mislil. Pa ni bilo nič od tega. /.../
Z ženo so nama, na primer, vdrli v avto, ko sva ga imela parkiranega v Trnovem, na
Fužinah pa nikoli, čeprav sva ga kdaj tudi pozabila odklenjenega. Po drugi strani se ti
v Fužinah razvažalci ne upajo pice z dvigalom prinesti do stanovanja, ker se bojijo, da
jim bo spodaj medtem bavbav požrl avto. V Trnovem ti jo seveda prinesejo. (Jan Jona
Javoršek 2005: 69)

\section{Fužinski bluz}

Prav to pestrost prebivalcev Novih Fužin predstavlja roman Andreja Skubica Fužinski bluz. Mitja Čander opozarja, da so Nove Fužine v zadnjem času trendovski prostor. Literarna kritika zaradi pogostosti Fužin in podobnih predmestnih naselij v sodobni slovenski književnosti uporablja celo izraz fužinska literatura. Fužine so »emblem urbanosti, s svojo jezikovno, etnično in socialno raznoterostjo so še najbliže velikomestnim koloritom. /.../ Fužine 
so nekakšen koncentrat tistega, kar zaznamuje celotno slovensko tranzicijo« (Čander 2005: 15).

Fužinski bluz, drugi roman Andreja Skubica, se dogaja 13. junija 2000, na dan nogometne tekme med Slovenijo in Jugoslavijo. V njem je raznolikost tega naselja prikazana s pomočjo štirih prvoosebnih pripovedovalcev, sosedov v desetem nadstropju fužinskega bloka: upokojene univerzitetne profesorice slovenskega jezika Vere Erjavec, nekdanjega voznika avtobusa, zdaj nepremičninskega posrednika, lastnika Fix Properties, $d$. o. o., srednjih štiridesetih Igorja Ščinkovca, dobrih trideset let starega hevimetalca, ki se preživlja s prodajanjem Salamonovega oglasnika, Petra Sokiča, in šestnajstletne srednješolke, po očetu Črnogorke, Janine Pašković. Vsak izmed njih govori svoj sociolekt.

Za temo tega prispevka je zborna slovenščina 65-letne Vere Erjavec popolnoma nezanimiva.

Jezik dvajset let mlajšega Igorja Ščinkovca je nižje pogovorno obarvan in daleč od višin intelektualnega jezika upokojene profesorice.

Ljubljanska pogovornost je stilizirana s pomočjo zmerne vokalne redukcije (npr. kolk namesto koliko - 158), pogovornih kratkih nedoločnikov, določnega člena ta- pri pridevnikih (tapravi - 158), na skladenjski ravni pa s povedmi, začetimi z naslonkami (Se mi obupno zdi, da bomo novega rabil. - 159), ali skladenjsko ne povsem pravilno sestavljenimi povedmi tipa Meni se zdi, da glih toyote, da so pisali, da imajo najmanj okvar na daljši rok, vse švabe so prešišali. (179), s težavami z dvojino: /.../ ekipe že stojijo, pripravljene na žogo (gre seveda za ekipi Jugoslavije in Slovenije - 218), predvsem pa z leksiko, v kateri najdemo dobre stare germanizme naših babic (prešaltati - na kaj bodo lahko Fix Properties, d. o. o., prešaltale, parkplac - 31, glih - 32, špricalo - 40, cajt - 98, kofe - 109, zalavfat - 158, fajn - 158, zic - 160, foh - 162), nekaj anglicizmov (keš - 158), predvsem pa se v njegovem jeziku kaže bogata dediščina nekdanje države južnih Slovanov. Najopaznejša je na leksikalni ravni (džeparac - 30, komad, dasa - 33, očerupan - 34, munjen - 35, prepucavat 97, zgaziti - 108, sudija - 160, našutirati - 162), v tem jeziku najraje preklinja (jebemti; Jebem mu mater! - 31, pizda mu materina - 32, mamu mu - 35, kurac - 37, zajebancija - 41, jebemti - 99, popizditi - 163), čeprav zna izražati svoje nezadovoljstvo tudi slovensko (Menda se bo zdaj še Zoki usral - 32, jebela cesta - 32, Pašković je navadna mala rit - 32, klinc - 35), pa tudi v kalkih iz štokavskih jezikov, npr. nisem jaz te sreče! - 31 ali Ne gre to tako - 32, pa tudi v skladnji (Tamala ima, da odraste pa gre študirat /.../ - 108).

S podobnimi, a veliko radikalneje uporabljenimi sredstvi je upodobljen ljubljanski sleng dobrih trideset let starega hevimetalca Petra Sokiča. Vokalna redukcija je veliko izrazitejša. Vzemimo za primer prvi Ščinkovčev odstavek:

Ma, lej ga pedra, kam se ti spravi. Lej ga! Ti klinc policajski! Pa bog te nima rad, tukaj se pred bloke zavija! Kje naj ti tukaj kdo ustavi! Pa kaj zdaj, a si boš zmislil, da sem na teh grbinah na gas pritiskal, ali kaj? Preklet pezde, samo da imaš kaj za delat. Pa to pa res ni za nikamor. (Skubic 2001: 28)

in ga primerjajmo s prvim Sokičevim: 
Ma, pizda, pa te kaplce. Kaplce kaplce. Vroče noči. Lučke - teh bo konc. Kaplce-spod pajske. Leze dol - se ti strga. To je od pira. Pir dela kaplce. Najprej na flaši-mrzli. Pol pa na koži. Kožo mam tud mrzlo. Se kar paca. Ampak pod pajsko. Za popizdit. (Skubic 2001: 9)

Tudi ostala stilizacijska sredstva so tu uporabljena $v$ bistveno večji meri kot pri Ščinkovcu. Preklinja še več od njega, večinoma po balkansko, dobrih starih germanizmov (pir, cajt, švoh) je manj kot pri Ščinkovcu, zato pa toliko več anglicizmov (npr. tivi, tu mač, kar nekaj je celih povedi, npr. Fresh college beaver; No such luck - verjetno gre za citate iz kakšnih priljubljenih hevimatalskih pesmi), dediščina nekdanje države pa ni opazna le v kletvicah (šta, vodna stvorenja, kučni ljubimac; evo, zora se zori, drugovi junaci; bunar, šetajo; Irena, ljubavi moja jedina, nikad ne prežaljena, Alo, konobarica - 209, šmeker); nižja pogovorna ljubljanščina je izražena še z besedami tipa $k v a$ in pogovornim mestnikom: na svojmu tastaremu naslovu? (84), na unmu koncertu (164).

Za temo tega prispevka je najbolj zanimiv sociolekt 16-letne Janine Pašković. Poglejmo njen prvi odstavek:

Jao, u pičku materinu, što sam mamurna, a nijesam ni pila toliko jučer. Kamoli da pijem, mamicu mu, ima da je sve to od pušenja, previše cigareta, mater im jebem pušačku, pušačima. E, тати mu, ovi žurevi usred tjedna, šta li mi to treba. (Skubic 2001: 42)

Slovensko spregovori šele v četrtem odstavku:

»Blo bi ful bolš, če bi bli mi zdele not pa neb mogli ven«, je reku Rožca. Sem misnla, da se bom poscala. "To bi blo ful bols.."Kako smo spizdil ven, sploh ne vem, sam da smo se pol nekak znajdl pri Valentinotu. (Skubic 2001: 42)

Podobno kot Petrova je tudi njena slovenščina ljubljanski sleng, le da je njena ljubljanščina še izrazitejša, vokalne redukcije močnejše, število besed neslovenskega izvora pa še večje: nekaj je germanizmov (zluftati - 42, pošteka - 44), veliko anglicizmov (Totalno bed - 42, kul-43, ful-47, lajf-132, bajla - 213).

Predvsem pa se v njenem govoru prepletata slovenščina in črnogorščina. Od tod verjetno izvirajo njene precej hude težave z dvojino: Dašo med odmorom nisem nič vidla, sam sej smo itak zmenene za pol. Ob šestih smo obedve že skupi dol pod blokom. (131) Težav nima vedno: Sam bolil naju je kurac.

Kadar misli ali govori slovensko, pogosto naletimo na neslovenske besede ali besedne zveze, npr. Mogoče, da bo kakšnega modela iz Štepanjca ulovu pa ga mal išamarao. (43) Še k Samiri na ljubavni sastanak ni mogu prit, ne da bi prej eno trubo potegnu. (55) Če bi mene vidl, kdo sem, bi bla takoj čez nočv $\check{c} u z i$. (138) Vendar pa gre pri tem praviloma za posamezne besede, stavki so sicer praviloma jezikovno enotni, kar pa ne velja za povedi:

Ne vem, ko sem na Mirsadovi gandži, opasna ti je to roba, se mi zmeri cajt tko nekak pospeši. (42) On se je sam naslanju na zid z unim svojim pirom, blazno kul -a, zdej se spomnim, vmes smo se ustavl v trgovini na Puharjevi pa kupl pir - a ona je iznenada odlučila da se sakrije neđe u žbunje. (43) A onda je niko nije jebao ni pet posto, a meni je postalo dosadno strojicom tipova, vsi so bli še zmeri zadeti ko afne. (43) Prid mal sem, stari, da ne budem sama. (55) 
Nekoliko večja jezikovna »mešanica« se pojavlja v redkih povedih tipa $\check{C} e$ jo kdo kej užal ali kej tazga, se ona zmer skrije nekam u žbunje pa čeka, da neko dođe i uvjerava je kako je svi volimo (43), kjer je pol drugega stavka slovenskega, pol pa črnogorskega.

Da v obeh jezikih veliko in grdo preklinja, je bilo razvidno že iz navedenih primerov.

Seveda je zanimivo vprašanje, kdaj uporablja kateri jezik.

Iz večernega prizora, v katerem pride domov s prijateljico Dašo in na svoje neljubo presenečenje odkrije, da sta oče in stric, ki sta Črnogorca, doma, je razvidno, da z njima govori v očetovem jeziku, kadar ni prisoten noben Slovenec ali vsaj nobeden izmed tistih, ki so zanjo pomembni. Ko se stric Mladen z njo vztrajno pogovarja črnogorsko, mu dvakrat odgovori slovensko, tretjič pa črnogorsko, a pri tem pomisli: Ove moje riječi mi zvuče malo čudno pred Dašom, ali jebiga, šta se tu može (181).

Bolj zapleteno je vprašanje, v katerem jeziku misli. Najprej je to povezano s tem, na kaj oziroma na koga misli. Ko v pravkar omenjenem prizoru odkrije, da sta oče in stric doma, začne premišljevati v očetovem jeziku. Ko začne komunicirati z Dašo, misli slovensko do trenutka, ko odpre vrata kuhinje, v kateri sta oče in njegov brat. Do preloma pride sredi povedi Daša se sezuje, a ja otvorim vrata od kuhinje (180).

Drugi dejavnik, ki vpliva na izbiro jezika, v katerem misli Daša (kot je že bilo velikokrat opozorjeno v zapisih o tej knjigi), pa so čustva - črnogorščina je njen čustveni jezik, slovenščina racionalni: Znamo svi da je bez veze, pa ipak nekako dolazimo. Menda sam zato, ker Mirsad upa, da bo kdo uletu iz Sulca pa da se bo hotu klofat. Mogoče, da bo kakšnega modela iz Štepanjca ulovu pa ga mal išamarao. Sej ni zdej, ni zdej cajt za to. (43) A onda je niko nije jebao ni pet posto, a meni je postalo dosadno s trojicom tipova, vsi so bli $\check{s}$ e zmeri zadeti ko afne. (43) V prvem primeru je prva poved izrazito čustvena, naslednje tri pa racionalnejše. Drugi primer je podoben, le da se to dogaja na ravni trostavčne povedi, v kateri sta prva stavka bolj čustvena, tretji pa njuna racionalna razlaga. Predvsem pa je izrazit primer tega čustveno nabiti lezbični prizor z Dašo, v katerem najprej misli slovensko, nato pa sredi stavka preklopi na črnogorščino: Pol ko je ona mene prva počela (252). Sledi črnogorščina, v kateri na Dašino veliko presenečenje tudi spregovori: "Lezi na krevet, Daša, ne boj se. Smiri se. Ššššš. (253; vse navedene strani iz Skubic 2001)

\section{Čefurji raus!}

Prav Janinin jezik je tisti, s katerim kaže primerjati jezik Fužinskega bluza z jezikom v romanu Čefurji raus! Gorana Vojnovića.

Skozi to knjigo nas vodi en sam prvoosebni pripovedovalec, najstnik, nadarjen košarkaš, sin bosanskih staršev Marko Đorđić, ki prav tako kot akterji Fužinskega bluza stanuje v Novih Fužinah, kjer se roman večinoma tudi dogaja. Vodi nas po žalostni poti od zmagovitega koša v zadnji sekundi do prisilnega 
odhoda v Bosno, s katerim naj bi se izognil odhodu v zapor zaradi sodelovanja pri kaznivem dejanju.

Vojnović je o nastanku knjige v televizijski oddaji Knjiga mene briga (prvič je bila predvajana 23. junija 2008) izjavil, da je bil glavni motiv za nastanek romana sam jezik, »fužinščina«. Dokler si je zgodbo predstavljal v pogovornem ali knjižnem jeziku, se mu ni zdela literarno zanimiva, razmišljal pa je o filmskem scenariju.

Kakšen je ta jezik?

Če bi v skladu s svojo predstavitvijo sociolektov v Fužinskem bluzu najprej prebral prvi odstavek prvega poglavja Zakaj nimam svojega fuzbal kluba, bi razen kletvic, ki pa jih uporablja tudi prenekateri prebivalec Murgel, ki so v romanu slovenski protipol »čefurskim« Fužinam, le s težavo našli še kakšen podkolpanski element. Namesto tega že v naslovu najdemo germanizem fuzbal, kasneje anglicizem sfajtati se, nekaj ljubljansko reduciranih besed, npr. tuki, pogovornih oblik, kakršna je očkatovih namesto očkovih, in elemente mladostniškega slenga, npr. ker je to češko, itak. Več pričakovanega besedja je že v naslednjem odstavku, kjer najdemo Boli jih patak!, šamari, lemati, papak, šetati, njuška (Vojnović 2008: 11-12). Kmalu vidimo, da so citati drugačni - najprej je tu kletvic poln citat govora Zvezdinih navijačev v srbščini, pa Zagrebčanov v hrvaščini. Do prave »fužinščine« se prvič dokopljemo v citatih dialogov z nekdanjih fužinskih nogometnh tekem - govorijo jo tisti, »ki so se naučili malo slovenščine, pozabili pa malo čefurščine in so zdaj govorili neko mešanico.« Njihovi dialogi so takile: »Podaj mi žogu! Zvio sam si gležanj! Ščipa me u hrbtenicu!« (Vojnović 2008: 15).

Ena najopaznejših razlik med romanoma je torej ta, da ima Fužinski bluz štiri pripovedovalce, izmed katerih je narodna tematika tematizirana le pri enem, Janini, Čefurji raus! pa ima enega pripovedovalca, ki skozi ves roman poleg opisovanja pripetljajev razglablja o razlikah med Slovenci in »čefurji«. Kot sem že omenil, najdemo v njegovem jeziku številne elemente slovenskega slenga, kakršni so številni anglicizmi, npr. bazrbitr, lajf, kul (vse 17), Ampak Olimpija je fakin šit! (17), hartatek (23), šejkati (41).

Čisto štokavščino najdemo v kletvicah, pri katerih gre Vojnović dlje od tega, kar pogosto slišimo po Sloveniji zunaj narodnostno močneje mešanih naselij: Jebo sam im kevu bogatu, kume! (19), Mamicu im nabijem pedersku! (23), jebala vas Amerika po sred šupka (47), Jebo vas Milan Kučan, da vas jebo! (58) in v citatih govora staršev ter drugih »pravih čefurjev«: »Ma nije tako! Je li me ti slušaaaš?«, »Jesi li rekla, da si stavila šerpu na balkon? Jesi li reklaaa?« (25)

Marko govori s starši bosansko, mladi med seboj pa govorijo v celoti neslovensko le v citatih: »Mogu samo da nas mrze, oni što nas vole!« (turbo folk pesem, ki jo poje Mitar Mirić), »Vozi Miško za Beograd!« »Može Miško i zatvorenih očiju!« (22)

Ljubljanska vokalna redukcija, ki jo najdemo v Fužinskem bluzu v toku zavesti treh pripovedovalcev, je tu bolj razvita le v dialogih:

»Boš vidu, da smo bli v Črnučah.» 
»Dej kup časopis pa poglej, kje je una lovska koča. Ziher je v črni kroniki, da smo jo razbil.«

»Sej je kle tut not črna kronika!«

Pripovedovalec govori cele stavke v bosanščini predvsem v posameznih stavkih in povedih: Odnio vrag šalu. (22) Ode mali kući plakajući! (36), I piši kući propalo (48) Jebem ti košarku i ko je izmisli (49) Odnijela ga magla (59).

Seveda pa najdemo tudi precej primerov prepletanja obeh jezikov. Največkrat najdemo posamezne izraze s štokavskega jezikovnega področja v slovenščini: Ali si najboljši na svetu ali pa šilji olovke, kot bi rekel Radovan (13).

Globlje v ustroj jezika priseljencev grejo primeri, ki imajo v slovenščini skladnjo, kakršna je značilna za jezike s štokavskega jezikovnega področja: /.../ mi je pa brez veze (12) ali To ne moreš verjet, kot bi rekel moj komšija Senad (17) ali za priseljence s področja bivše Jugoslavije z značilnim pregibanjem: Ker katero naselje ima svoje viceve? (177) ali Pa pokal je vzel s sabo in jim razlagal, da je njegov sin Marko zmagao in da ga malo proslavljaju in da se malo veselijo, ker je dao koš v zadnjoj sekundi in je dobio pokal za najboljega strelca turnira (20). Skozi ves roman dosleno piše na Fužinama (npr. 45).

$\mathrm{V}$ podobno kategorijo sodijo kalki iz štokavskega jezikovnega področja v slovenščini: Kere buče (45) /.../ kaj mu bo delalo /.../ (46) Ampak to mi je sedlo (178).

Prepletanje med jezikoma poteka tudi v nasprotni smeri: ko priseljenci govorijo svoj materni jezik, so v njem elementi slovenščine, npr: Jebem jim jst mater! (24), In Duško ga se propio (48), "Zar ne možeš jedan trening preskočit pa malo pogledat tu zgodovinu? Što se nisi javio, da te vpraša? (60)

$\mathrm{V}$ naslednjih primerih se je težko odločiti, kateri jezik je osnovni, katerega elementi pa so mu dodani:

Slažeš šuplje po domače (28); Cigara, ena, dve, to ni nič takega, saj je tudi Radovan pušil, ko je bil mlad, ampak če bi popušil en džoint, letio bi kroz prozor naglavačke sa trinaestog sprata /.../ Ode glava. (36); Userem se živ, ko jo vidim (41); Ko sem tako hodal in se delal, da sem najjači in da ne jebem žive sile in da me zaboli uvo za cel svet, me je zjebal zvok tapkanja iz dvorane (46); Mene je jebala una pederčina in jaz sem završio priču (107); Za nagrado, ker sem enemu Olimpijinemu klokanu prošetal zubiće levo desno po brnjici, sem bil suspendiran za en teden (44).

Zabaven primer tega je pripovedovalčev dialog z očetom: »Jesi napiso domaču nalogu?" "Aha! « »Jel danas tekma? « »Sutra." (32)

Najmočnejši pripovedovalčev čustveni izliv v knjigi se začne v slovenščini, nato preide $\mathrm{v}$ jezik svojih staršev, ki po kratkem intermezzu v slovenščini dokončno prevlada:

Ranka me poskuša ustavit, a ne more. Naenkrat nešto u meni pukne i rasplačem se skroz. Do konca. Urlam, a suze teku i ne mogu ih više zadržat. Udaram šakama u zid $i$ urlam. Nikad u životu nisam ovako plakao. Tresem se i plačem i jedva dišem. Sve, što se skupljalo, sad se skupilo i najednom izletilo iz mene. Tuga, muka, jad, samo bijesa više nema. Plačem ko malo dijete. I Ranki dozvolim, da me zagrli, i plačem joj na ramenu. 
Gotov sam. Ne mogi prestat, nema šanse. Osjećam se, ko da je sve, što se skupljalo danima, sad procurilo iz mene velikim mlazom. Puko sam. Ko malo dijete. Na maminom ramenu. Mokrom od mojih suza. (104-105; vse navedene strani iz Vojnović 2008)

\section{Spremeni me}

Ker sem svoj prispevek začel z utopijo iz 19. stoletja, naj ga zaključim z nekaj mislimi o morda najnovejši slovenski antiutopiji (čas utopij je žal minil), dobro leto starim romanom Andreja Blatnika Spremeni me, ki se dogaja v prihodnosti. Če za Fužinski bluz vemo natančen datum dogajanja, ga lahko za Čefurji raus! sklepamo s pomočjo debate o tem, »a ima več šans za predsednika Amerike pička ali niger« (Vojnović 2008: 47), glede Blatnikovega romana pa na datum dogajanja sklepamo s pomočjo prišleka iz Argentine in njegovega domobranskega dedka, ki svoje dolgo življenje zaključi proti koncu romana. Poleg tega lahko vsak malo boljši poznavalec Ljubljane že na prvih straneh prepozna nekaj prizorišč - hostel Celica, bližnje kulturno ministrstvo, avtomehanično delavnico, narodopisni muzej in ambulanto za pomoč odvisnikom.

$\mathrm{V}$ črni podobi ne preveč oddaljene prihodnosti lahko, kot je to pri antiutopičnih delih običajno, prepoznamo preštevilne elemente današnjega sveta, ki pa so toliko stopnjevani, da se nam (vsaj zaenkrat še) zdijo absurdni: narava je že tako močno načeta, da so umetna drevesa veliko lepša od naravnih, hrana je sintetična, pravo sadje je na razpolago le na črnem trgu, ljudje so oboroženi, stanovanja dobro zavarovana, prodaja organov lastnega telesa pogost način zaslužka, svetu vladajo mogočne korporacije itd.

Knjiga je napisana v zglednem zbornem jeziku, ki ga krasijo izvrstni neologizmi, npr. stičnik, globaleščina, vikipedirati se. Od zbornega jezika odstopa le nižji pogovorni jezik brezdomcev. Z jezikom priseljencev iz nekdanjih bratskih republik se Blatnik ne ukvarja, begunci pa so skrbno zaprti v begunski center.

\section{Sklep}

V Stritarjevi Deveti deželi, državi s slovansko ljudovlado, se govori najlepša slovenščina. Pozneje smo Slovenci živeli v takšni državi, posledice tega obdobja pa so zelo opazne v narodnostno najbolj mešanem ljubljanskem blokovskem naselju Nove Fužine, ki je prizorišče dveh obravnavanih romanov.

Skubičev Fužinski bluz s pomočjo skrbno izklesanih sociolektov štirih junakov skozi njihove notranje monologe prikaže pestrost prebivalstva tega naselja. Upokojena profesorica govori zborno slovenščino, nižje pogovorna slovenščina petinštiridesetletnega nepremičninskega posrednika je predvsem polna srbokroatizmov, precej manj je germanizmov, anglicizmi pa so redki. Sociolekt predstavnika naslednje generacije, Petra Sokiča, je še nižje pogovorna slovenščina, ki je polna srbokroatizmov in anglicizmov, najbolj zanimiv pa je sociolekt šestnajstletne Janine Pašković, s pomočjo katerega je prikazana 
razdvojenost in izgubljenost druge generacije priseljencev, saj ne le govori, temveč tudi misli zdaj v enem, zdaj v drugem jeziku, ki ju do neke mere tudi meša; pri tem stavki (z izjemo leksikalne ravni) ostajajo jezikovno enotni, kar pa ne velja za povedi.

V Fužinskem bluzu torej Janina kot pripovedovalka govori enkrat v slovenščini, drugič v črnogorščini, v romanu Čefurji raus! Gorana Vojnovića pa pripovedovalec govori slovenščino, ki je »obogatena«s srbokroatizmi, pa tudi z anglicizmi in drugimi slengizmi. Izraziteje je novofužinska mešanica jezikov razvidna iz dialogov. Z njeno pomočjo je prikazana izgubljenost ljudi, ki so zapustili dom, niso pa se popolnoma vživeli v novo okolje, kar se kaže tudi v njihovem mešanju maternega jezika z jezikom okolja, saj nobenega ne obvladajo pretirano dobro, hkrati pa je seveda prav jezik eden od razlogov njihovega težjega vživljanja. Tudi v tem romanu pripadniki druge generacije močnejša čustva izražajo v jeziku svojih staršev.

V grozljivem okolju antiutopije Spremeni me, ki se dogaja v ne tako zelo oddaljeni prihodnosti, polni prepoznavnih, a stopnjevanih elementov današnjega sveta, je slovenski jezik v odličnem stanju, kar je razvidno iz domiselnih neologizmov, s katerimi so poimenovane tehnične novosti. Jezikovno je stiliziran le nižje pogovorni jezik brezdomcev, in ko eden izmed njih prizna, da je v resnici uporniški izobraženec, takoj začne govoriti zborno. Tematika priseljencev se $\mathrm{v}$ tem romanu ne pojavlja.

\section{LITERATURA}

Andrej BLATNIK, 2008: Spremeni me. Maribor: Litera.

Mitja ČANDER, 2005: Fenomen Skubic. Fužinski bluz. Gledališki list SNG Drama. Ur. Jan Jona Javoršek. Ljubljana: SNG Drama Ljubljana. 14-17.

Danilo DOLENC, 2007: Priseljevanje v Slovenijo z območja nekdanje Jugoslavije po drugi svetovni vojni. Priseljenci. Ur. Miran Komac. Ljubljana: Inštitut za narodnostna vprašanja. 69-102.

Jan Jona JAVORŠEK, 2005: Socialni nadrealizem. Fužinski bluz. Gledališki list SNG Drama. Ur. Jan Jona Javoršek. Ljubljana: SNG Drama Ljubljana. 66-70.

Miran KOMAC idr. 2007: Pa mi vi povejte, kaj sem!!!? Študija o etnični raznolikosti $v$ Mestni občini Ljubljana. Ljubljana: Fakulteta za družbene vede.

Vesna LESKOŠEK, 2005: Esej o slepoti (po slovensko). Fužinski bluz. Gledališki list SNG Drama. Ur. Jan Jona Javoršek. Ljubljana: SNG Drama Ljubljana. 31-37.

Rastko MOČNIK, 2005: Kjer je Ljubljana skoraj metropola. Fužinski bluz. Gledališki list SNG Drama. Ur. Jan Jona Javoršek. Ljubljana: SNG Drama Ljubljana. 26-28.

Andrej E. SKUBIC, 2001: Fužinski bluz. Ljubljana: Študentska založba.

Josip STRITAR, 1954: Zbrano delo 4. Ur. France Koblar. Ljubljana: DZS. 
Goran VOJNOVIĆ, 2008: Čefurji raus! Ljubljana: Študentska založba. Wikipedija: Nove Fužine http://sl.wikipedia.org/wiki/Nove_Fu\%C5\%BEine, 24. april 2009.

\section{DEVETA DEŽELA/THE NINTH COUNTRY, IMAGES OF POST-YUGOSLAV PRESENT AND AN ANTI-UTOPIAN IMAGE OF THE (EUROPEAN?) FUTURE}

The Ninth Land by Josip Stritar, is an ideal state, where children are bullied by Europe, located on a deserted island. The most beautiful, sweet-voiced Slovene language which is spoken on the island is a result of its isolation. Today Slovenia is not an island; it has behind it a good seven decades of the influence of its South Slavonic neighbours, which left marks on the language.

This article focuses on a linguistic analysis of the novels Fužinski bluz by Andrej Skubic and Čefurju raus! by Goran Vojnović. The setting in both novels is Nove Fužine, the largest urban settlement in Ljubljana, where a large number of immigrants from the former Yugoslavia and their descendants live alongside purebred Slovenes from all kinds of social backgrounds.

The diversity of the settlement's residents influenced the formation of some interesting sociolects. In Fužinski bluz the variegation is presented with the help of four very different narrators, each of whom speaks a different sociolect : a professor of Slovene language speaks literary Slovene, a real estate agent uses a less refined Slovene, a youth who listens to heavy metal music speaks slang, and the sixteen-year-old descendant of Montenegrin immigrants alternately uses Slovene slang and the language of her parents. Her sociolect is comparable to the language in Vojnović's novel. The narrator's predominantly Slovene speech is »enriched « with numerous elements from the Shtokavian linguistic region. It is possible to find a real mixture of languages in the dialogue.

As a counterweight to Stritar's introductory utopia, the article concludes with some thoughts on the antiutopian Change Me by Andrej Blatnik. In this novel we find a rather dark vision of Slovenia in a not particularly distant future; in the novel we can recognize numerous phenomena of our everyday lives. Apart from the literary language, only the lower colloquial language of the homeless stands out, while technical innovations include some excellent neologisms. 